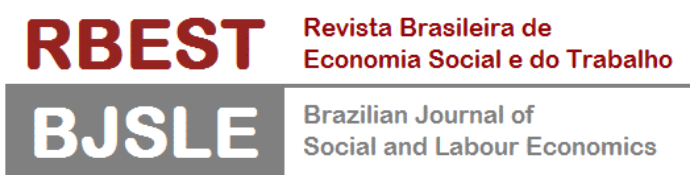

\title{
DOSSIÊ: INDÚSTRIA 4.0
}

\section{Potenciais impactos da Indústria 4.0 sobre os trabalhadores: Percepções de brasileiros e portugueses}

\author{
Alexandre Junqueira* \\ Yuri Oliveira de Lima** \\ Jano Moreira de Souza***
}

\begin{abstract}
Resumo
Desde a Revolução Industrial houve transformações profundas nas condições de trabalho. Em cerca de 200 anos, foram dados saltos do ponto de vista tecnológico, econômico e social. O século XXI trouxe descobertas que estão desencadeando alterações bastante significativas, com forte impacto sobre os trabalhadores. Este estudo verificou a expectativa de brasileiros e portugueses sobre os desafios das novas tecnologias. Os resultados mostram que boa parte das pessoas ainda desconhece ou conhece pouco as implicações das inovações digitais, mas assumem uma postura apreensiva em relação ao futuro, demonstrando incertezas acerca dos benefícios e até certa "fobia digital". Há um consenso de que muitas mudanças irão ocorrer por causa da Indústria 4.0 e será difícil encontrar bons empregos. Além disso, fica evidente que governos, empresas, escolas e indivíduos têm grande reponsabilidade para preparar a força de trabalho para enfrentar os desafios da quarta revolução industrial.
\end{abstract}

Palavras-chave: Indústria 4.0; Inovação tecnológica; Emprego; Fobia digital.

JEL: J24, O10, 033, 057.

* Mestre em Economia Social, Universidade do Minho (UMinho), Portugal.

Orcid: https://orcid.org/0000-0003-0797-9787

E-mail: prof.aj@gmail.com

** Universidade Federal do Rio de Janeiro (UFRJ), Brasil.

Orcid: https://orcid.org/0000-0002-6662-9771

E-mail: yuriodelima@cos.ufrj.br

*** Universidade Federal do Rio de Janeiro (UFRJ), Brasil.

Orcid: https://orcid.org/0000-0001-5080-1955

E-mail: jano@cos.ufrj.br 


\title{
Potential impacts of Industry 4.0 on workers: Perceptions of Brazilians and Portuguese
}

\begin{abstract}
Since the Industrial Revolution there have been profound transformations in working conditions. In about 200 years, technological, economic, and social leaps have been made. The 21st century brought discoveries that are triggering quite significant changes, with a strong impact on workers. This study checked the expectations of Brazilians and Portuguese about the challenges of the new technologies. The results show that most people still have little or no knowledge about the implications of digital innovations, but assume an apprehensive attitude in relation to the future, showing uncertainty about the benefits and even a certain "digital phobia". There is a consensus that many changes will occur because of Industry 4.0 and good jobs will be hard to find. Moreover, it is clear that governments, companies, schools, and individuals have a great responsibility to prepare the workforce to meet the challenges of the fourth industrial revolution.
\end{abstract}

Keywords: Industry 4.0; Technological innovation; Employment; Digital phobia.

\section{Impactos potenciales de la Industria 4.0 en los trabajadores: Percepciones de brasileños y portugueses}

\begin{abstract}
Resumen
Desde la Revolución Industrial se han producido profundas transformaciones en las condiciones de trabajo. En unos 200 años, se dieron saltos desde el punto de vista tecnológico, económico y social. El siglo XXI trajo consigo descubrimientos que están provocando cambios muy significativos, con fuerte impacto en los trabajadores. Este estudio verificó las expectativas de brasileños y portugueses sobre los retos de las nuevas tecnologías. Los resultados muestran que la mayoría de las personas todavía tienen poco o ningún conocimiento de las implicaciones de las innovaciones digitales, pero se muestran recelosas ante el futuro, mostrando incertidumbre sobre los beneficios e incluso una cierta "fobia digital". Hay consenso en que se producirán muchos cambios debido a la Industria 4.0 y que será difícil encontrar buenos empleos. Además, está claro que los gobiernos, las empresas, las escuelas y los individuos tienen la gran responsabilidad de preparar a la mano de obra para afrontar los retos de la cuarta revolución industrial.
\end{abstract}

Palabras clave: Industria 4.0; Innovación tecnológica; Empleo; Fobia digital.

\section{Incidences potentielles de l'industrie $\mathbf{4 . 0}$ sur les travailleurs: Perceptions des Brésiliens et des Portugais}

\section{Résumé}

Depuis la révolution industrielle, les conditions de travail ont connu de profondes transformations. En 200 ans environ, des bonds en avant ont été réalisés du point de vue technologique, économique et social. Le 21 e siècle a apporté des découvertes qui déclenchent des changements très importants, avec un fort impact sur les travailleurs. Cette étude a permis de vérifier les attentes des Brésiliens et des Portugais face aux défis des nouvelles technologies. Les résultats montrent que la plupart des gens ont encore peu ou pas de connaissances sur les implications des innovations numériques, mais qu'ils appréhendent l'avenir, montrant une incertitude quant aux avantages et même une certaine "phobie du numérique". Tous s'accordent à dire que l'industrie 4.0 entraînera de nombreux changements et que les bons emplois seront difficiles à trouver. En outre, il est clair que les gouvernements, les entreprises, les écoles et les particuliers ont une grande responsabilité dans la préparation de la maind'œuvre à relever les défis de la quatrième révolution industrielle.

Mots-clés: Industrie 4.0; Innovation technologique; Emploi; Phobie numérique. 


\section{Introdução}

As revoluções industriais são períodos intensos de mudanças, principalmente dos sistemas produtivos que, de forma iterativa, acabam por modificar a sociedade como um todo. Nestes períodos históricos, as pessoas reagiram ao que estava ocorrendo e ao que viria a ocorrer. Estas reações variavam desde o medo do desemprego tecnológico até a esperança por uma sociedade mais justa. Os sentimentos ao longo da história foram os mais diversos e variaram de acordo com o grupo social.

A Revolução Industrial original, talvez o mais drástico destes momentos, não pode ser resumida à invenção da máquina a vapor, ou à passagem do sistema de produção artesanal para a produção fabril. Houve uma mudança completa da sociedade. No século XVIII, a maior parte das sociedades europeias se baseava numa economia mercantil, combinando a atividade agrícola com a atividade artesanal e a manufatura simples.

A Revolução Industrial foi um processo longo, no qual mudanças tecnológicas afetaram de maneira intensa as relações de trabalho. A Inglaterra foi, sem sombra de dúvidas, a pioneira no desenvolvimento mecanicista da produção e o setor que primeiro aderiu às novas tecnologias foi o têxtil, no qual se tornou possível avaliar os impactos causados pela introdução dos novos métodos de fabricação, em especial a desqualificação da força de trabalho. O setor têxtil, que durante muito tempo foi caracterizado pelo artesanato, com a chegada das novas tecnologias, registrou uma drástica redução de postos de trabalho, que causou forte agravamento dos problemas sociais.

É nesse contexto que surge, em 1812, o movimento dos Ludditas, que ofereceu resistência às transformações tecnológicas que ocorriam no período, e mudavam de forma drástica o próprio estilo de vida desses trabalhadores. Esse movimento, composto por um grupo de artesãos ingleses, realizou uma série de protestos contra a automação das fabricas têxteis e chegaram a destruir as máquinas que, na percepção deles, estavam "roubando" seus empregos (Autor, 2015).

Ao longo do século XIX, à medida em que aumentavam o número de teares mecânicos (de 2.400 em 1813 para 224.000 em 1850), o número de tecelões manuais, que havia crescido até meados da década de 1820 (chegando a aproximadamente 250.000), diminuiu para pouco mais de 100.000 no começo da década de 1840 e para cerca de 50.000 em 1850 (Hobsbawm, 2000). Com a segunda revolução industrial, no último quarto do século XIX e início do século $X X$, a falta de trabalho e os baixos salários fizeram que um grande contingente de pessoas deixasse a Europa e imigrasse para outras partes do mundo à procura de uma vida melhor. Muitos seguiram para as Américas (Oliveira, 2004). 
Durante a terceira revolução industrial, no último quarto do século $X X$, ocorreu novamente aumento do desemprego nos países mais desenvolvidos. A divergência na explicação das causas do desemprego envolveu diferentes percepções com relação às mudanças tecnológicas e seus impactos no nível de emprego, que colocaram em disputa trabalhadores, empresários, políticos e outros grupos sociais relevantes.

Atualmente, a quarta onda da revolução industrial, caracterizada pela integração e controle da produção a partir de sensores e equipamentos conectados em rede e da "fusão do mundo real com o virtual" (Confederanção Nacional da Indústria [CNI], 2016), tem sido chamada no meio empresarial de "Indústria 4.0". Este termo foi cunhado na Alemanha, em 2011, a partir de um projeto desenvolvido pelo governo alemão que visava o desenvolvimento de inovações tecnológicas com o objetivo de aumentar a competitividade industrial por meio de "fábricas inteligentes" (Amorim, 2017). A Indústria 4.0 vem promovendo mudanças de forma acelerada, e com ela novos sentimentos surgem em relação ao futuro do trabalho.

No Brasil, a adoção de novas tecnologias no mercado de trabalho é uma tendência, conforme apontam Lima et al. (2019), Lima et al. (2021) e Albuquerque et al. (2019), nas próximas décadas, mais da metade dos postos de trabalho do país têm alta probabilidade de serem automatizados. Portugal pode ser considerado outro país em que as transformações digitais tendem a rapidamente substituir grande parte da força de trabalho humana (Duarte, 2019).

A COVID-19 tem sido um processo catalisador dessas mudanças do mercado de trabalho, inovações que levariam anos ou até mesmo décadas para se consolidar, foram aceleradas pelo contexto pandêmico e algumas dessas transformações agravaram ainda mais a situação do desemprego no Brasil e no mundo. Desde o início da pandemia percebeu-se que a adoção das novas tecnologias avançaria de forma rápida por conta da necessidade de se manter o funcionamento das empresas, devido aos protocolos sanitários de distanciamento social e pela necessidade de otimizar os custos das operações (Blit, 2020; Chernoff \& Warman, 2020; Ding \& Molina, 2020; McKinsey Global Institute [MGI], 2020, p. 8; World Economic Forum [WEF], 2020).

Já existem alguns indicativos de que o processo de automação da produção tem se intensificado durante o período da pandemia. Um levantamento recente do Fórum Econômico Mundial demonstrou que $50 \%$ dos empregadores estão planejando acelerar a automação de tarefas como uma resposta à COVID-19, porcentagem que chega à 68\% no Brasil (World Economic Forum, 2020). Por sua vez, um levantamento feito pela McKinsey Global Institute (McKinsey Global Institute, 2020) com 800 executivos mostrou que 67\% das empresas estavam, desde o início da pandemia da COVID-19, adotando processos de automação e de 
"inteligência artificial" (IA) de maneira significativamente acelerada (20\%) ou ligeiramente acelerada (47\%).

Os efeitos da aceleração da automação já estão sendo percebidos, principalmente por trabalhadores de serviços de atendimento presencial que, por conta do risco, têm sido substituídos por sistemas automáticos para que as empresas não parem de prover seus serviços (Chernoff \& Warman, 2020). Regionalmente, o efeito da automação durante a pandemia está sendo sentido, como mostra, por exemplo, uma análise recente feita pelo Federal Reserve Bank da Filadélfia (EUA) que demonstrou que trabalhadores em ocupações mais automatizáveis perderam mais seus empregos durante a pandemia do que os que têm um menor risco de automação (Ding \& Molina, 2020).

A história tem nos ensinado que, apesar de atividades desaparecerem, outras surgiram e, embora essas mudanças tenham causado problemas, com o passar do tempo, novas ocupações supriram as anteriores e novos empregos nunca deixaram de ser criados. Neste sentido, a discussão atual sobre o emprego, diante das mudanças em curso, talvez não seja se ele irá deixar de existir, mas, se a sociedade está preparada para trabalhar e viver nesta nova realidade. $E$, ainda, sendo as mudanças inevitáveis e muito rápidas, como podemos tirar o melhor proveito delas, de preferência que seja coletivo e não restritivo.

Embora haja grande interesse dos pesquisadores em saber quais são possíveis impactos das novas tecnologias no mercado de trabalho, estudos empíricos a esse respeito ainda são escassos. Um dos motivos apontados é o fato de que os dados estatísticos sobre as novas tecnologias como IA, robótica, entre outras, ainda são muito limitados e os estudos econômicos nesta área ainda estão em estágio inicial. Assim sendo, uma das possíveis abordagens para contornar a indisponibilidade de dados estatísticos é a realização de pesquisas de campo com empresas ou indivíduos para coletar informações para avaliações subjetivas destes acerca do tema (Morikawa, 2017).

Dessa forma, o presente estudo apresenta um levantamento realizado com pessoas do Brasil e de Portugal, que busca entender as suas percepções com relação à atual transformação digital e seus possíveis impactos sobre o futuro do trabalho.

Na sequência, o artigo está organizado da seguinte forma: a seção 1 apresenta estudos que também procuraram, de alguma forma, entender a percepção das pessoas com relação aos impactos das mudanças tecnológicas atualmente em curso; a seção 2 apresenta a metodologia utilizada para levantamento dos dados; a seção 3 traz os resultados da pesquisa de campo; a seção 4 discute os resultados do levantamento à luz de estudos similares; por fim, a última seção apresenta algumas considerações finais. 


\section{Estudos relevantes sobre o tema}

Procuramos identificar pesquisas recentes que abordam a percepção de trabalhadores ou futuros trabalhadores sobre os possíveis impactos da quarta revolução industrial e da Indústria 4.0 sobre o mercado de trabalho e o emprego.

O "medo tecnológico" pode ser constatado em diversos estudos realizados nos mais variados países. Nos EUA encontramos a maioria destes estudos; com os avanços em áreas como robótica, IA, e biotecnologia surge, uma vez mais, a ameaça do desemprego tecnológico (McClure, 2018). Grande parte da sociedade americana está apreensiva e amedrontada com o ritmo acelerado destas mudanças. Em seu artigo, o autor explora como os "tecnofóbicos" (pessoas que apresentam temores frente a tecnologia, o desemprego e os problemas financeiros) reagem a estas mudanças, e as implicações desta "fobia" para os indivíduos.

Realizada em 2015, com 1.541 entrevistados maiores de 18 anos, a pesquisa aponta que os "tecnofóbicos", têm em média 52 anos, são do sexo feminino, têm formação superior, são casados, vivem em áreas metropolitanas, e se identificam politicamente como conservadores (McClure, 2018). Os dados também demonstram que mulheres, minorias nãobrancas e pessoas com menor grau de instrução são as que mais relataram ter medos relacionados às tecnologias, e, mostram ainda, que esse medo está relacionado com a falta de conhecimento destas pessoas sobre o tema. Entre os efeitos da "tecnofobia", aparecem problemas de saúde, relacionados à ansiedade, o medo do desemprego e a insegurança financeira (McClure, 2018). Além disso, o estudo de McClure (2018) sugere que, conforme aumenta o nível educacional das pessoas, há uma significativa redução frente aos temores tecnológicos. Tal constatação já havia sido feita por outros economistas (Acemoglu, 2002; Acemoglu \& Autor, 2011; Autor, Levy, \& Murnane, 2003).

Outro estudo relevante sobre o tema foi conduzido por Dodel e Mesch (2020), que procurou analisar as percepções dos estadunidenses em relação aos impactos da automação nos locais de trabalho. Os autores partiram da hipótese de que indivíduos em posições mais elevadas no mercado de trabalho são menos propensos à sensação de que seus empregos estão ameaçados e, portanto, têm visões mais otimistas em relação as mudanças tecnológicas e o emprego. Os autores analisaram dados de 2.510 entrevistados para avaliar quais são as características sociodemográficas e de trabalho relacionadas às visões positivas e negativas acerca das novas tecnologias sobre empregos e renda.

Os resultados mostraram que os trabalhadores mais velhos expressam percepções mais negativas sobre o impacto das novas tecnologias que os mais jovens. Além disso, pessoas que desenvolvem tarefas manuais ou físicas também são mais temerosas. Em relação ao gênero, não houve diferenças significativas entre a percepção dos homens e das mulheres. 
No entanto, pessoas com maior grau de escolaridade e de nível de rendimentos revelam uma postura mais positiva diante das novas tecnologias, corroborando com a hipótese inicial. Outra variável sensível, captada pelo estudo, foi que indivíduos brancos acreditam ter menos probabilidade de perda de emprego que os demais. Dos participantes do estudo, 4,6\% perderam o emprego ou sofreram redução salarial por conta da automação e 16\% acreditam que as novas tecnologias tiveram um impacto negativo em seu trabalho. $O$ estudo concluiu também que as novas tecnologias podem gerar ansiedades sociais e que essas ansiedades são mais acentuadas entre os setores mais vulneráveis da sociedade (Dodel \& Mesch, 2020).

Com base em dados do Pew Research Center, Wike e Stokes (2018, September) comparam a apreciação de pessoas em dez países sobre as transformações no mercado de trabalho, na economia e nas relações sociais, decorrentes da adoção de novas tecnologias nos diferentes países. Numa perspectiva sobre o futuro, o estudo verifica como as pessoas encaram os desafios das novas tecnologias nos próximos 50 anos, abordando não apenas a possibilidade de substituição de mão de obra humana por robôs e IA, como também questões sobre aumento da desigualdade, dificuldades em encontrar empregos, eficiência econômica, remuneração, responsabilidade das instituições e dos demais atores no desenvolvimento das habilidades e formação para alcançar sucesso no futuro.

Os resultados apontam que a maioria dos entrevistados acredita que as máquinas irão substituir muito do trabalho que hoje é realizado por humanos e que isso irá acarretar maior desigualdade social, dificuldade em conseguir empregos e redução salarial. Além disso, os entrevistados apontam que governos, escolas, pessoas e empresas têm grande reponsabilidade pela qualificação dos indivíduos para atuar na Indústria 4.0.

Na União Europeia, Dekker, Salomons, e van der Waal (2017) procuraram verificar se o medo dos robôs no trabalho é maior entre os indivíduos que são mais propensos a serem afetados pela adoção de novas tecnologias, como: desempregados, profissionais menos qualificados que executam atividades rotineiras e repetitivas. Além disso, os autores verificaram se existem diferenças significativas em relação ao receio frente ao avanço da robótica em países com políticas públicas de proteção ao trabalho (como subsídios aos desempregados, sindicatos fortes), comparados a países onde tais medidas são menos marcantes.

Os resultados mostraram que o medo dos robôs cai à medida que aumenta o nível escolar e que os desempregados demonstram ter mais medo dos robôs no trabalho que os trabalhadores empregados. Os trabalhadores de "colarinho branco" (funcionários administrativos e de escritórios) demonstram níveis mais elevados de medo dos robôs no trabalho do que os gestores profissionais. Outro dado interessante nesta pesquisa é que o medo de automação entre as mulheres é maior que dos homens. A análise macro mostra que 
em países com altas taxas de desemprego ou com sindicatos fracos há maior medo de robôs no trabalho, no entanto, o crescimento do PIB e a rigidez da legislação trabalhista não são estatisticamente significativos para explicar o medo da automação.

Outro estudo sobre como as pessoas reagem às novas tecnologias no mercado de trabalho foi conduzido na Bulgária por Ivanov, Kuyumdzhiev e Webster (2020, April 18). Nele, foram ouvidos 502 entrevistados, búlgaros maiores de 18 anos, residentes na Bulgária e em outros países.

Os resultados demonstraram que o medo da substituição de seres humanos por máquinas é baixo entre os entrevistados, embora, presente na amostra, estes indivíduos não fazem parte de um grupo demográfico claramente definido. A variável sexo não é determinante para aferir o receio em relação a automação tecnológica entre os búlgaros. Tão pouco, as variáveis renda, educação ou local de moradia, entretanto, se tais variáveis não parecem condicionar a reação das pessoas frente as mudanças tecnológicas, a idade acaba por ser uma determinante neste grupo. Enquanto os mais jovens demostram esperança e flexibilidade frente as transformações, os mais velhos estão menos propensos a se requalificar para enfrentar os desafios do mercado de trabalho tecnológico. Além disso, os resultados revelam que o pouco medo de automação na Bulgária está associado a percepção de um processo de desumanização da sociedade, e não da substituição de homens por máquinas.

Morikawa (2017), por sua vez, realizou no Japão a análise de uma pesquisa conduzida com 10.000 indivíduos, estratificados por sexo, idade e região, para checar os possíveis impactos da IA e da robótica no emprego. Este estudo avalia, do ponto de vista dos trabalhadores, quais os que percebem maior risco de seus empregos serem substituídos pelas novas tecnologias. A hipótese inicial do estudo é a de que, quanto maior o grau de qualificação de um indivíduo, maior será sua percepção acerca dos impactos das novas tecnologias. Além disso, o estudo avalia também a aceitabilidade dos consumidores em relação aos robôs de serviço.

As conclusões das análises mostram que cerca de $30 \%$ dos trabalhadores japoneses, principalmente os mais jovens, têm medo de que seus empregos sejam substituídos por novas tecnologias. Por outro lado, os resultados sugerem que serviços pessoais como assistência infantil, assistência médica e educação, são menos suscetíveis de serem substituídos por IA e robótica, porque os consumidores preferem que estes serviços sejam prestados por humanos (Morikawa, 2017).

Como pode ser observado nos estudos apresentados, a "fobia digital" é consensual entre a maioria dos trabalhadores nos diversos países, principalmente entre os mais vulneráveis. No entanto, uma literatura recente, procurou testar até que ponto as visões 
individuais dependem não apenas das capabilidades dinâmicas de cada um, mas também das suas crenças com relação a fatores externos e das suas expetativas frente ao futuro. Níveis de confiança individual demasiadamente elevados podem permitir comportamentos subótimos no processo de tomada de decisão (Heidhues, Kőszegi, \& Strack, 2018; Marray, Krishna, \& Tang, 2020).

Não são claros os mecanismos que permitem compreender estas ligações, aparentemente correlacionados com a resposta individual aos feedbacks gerados no próprio processo de aprendizagem. Outros autores, como Hainguerlot, Vergnaud, e de Gardelle (2018), sublinham que, na inexistência de feedbacks, os indivíduos usam o seu grau de confiança, a partir do conhecimento do meio envolvente e dos seus desafios como forma de fundamentar seu comportamento futuro. Com base num estudo de natureza experimental, estes autores concluem a existência de uma relação entre a capacidade para avaliar as capabilidades individuais e para aprender.

Briel et al. (2020) abordam o impacto sobre a confiança nos salários que os estudantes universitários, prestes a entrar no mercado de trabalho, esperam vir a ganhar. Os autores deste estudo partem de um inquérito lançado numa universidade alemã, constroem um índice de confiança e mostram que está relacionado com o gênero e com os salários efetivos. Estudantes do sexo masculino, na amostra, revelam-se significativamente mais confiantes.

Os trabalhos supracitados revelam que os feedbacks recebidos nas diversas pesquisas sobre o tema, incluindo essa, podem estar "contaminados" por tais prerrogativas, no entanto, o fato de tais preocupações serem latentes em diversos países, com características sociais e culturais tão distintas, deve ser motivo de debates e avaliações mais aprofundadas.

Conforme pudemos observar há fatores convergentes nos diversos estudos relacionados anteriormente, a "fobia digital" é mais recorrente entre trabalhadores nos níveis hierárquicos mais baixos, entre mulheres, grupos étnicos historicamente marginalizados e principalmente entre pessoas com menor grau de instrução. Além disso, os dados apontam para um aumento das desigualdades sociais à medida em que as novas tecnologias vão ganhando mais espaço. Diante de tais constatações, cabe-nos perguntar se em países como o Brasil ou mesmo Portugal, onde a transformação digital ainda não aconteceu de forma intensa, se algumas destas tendências se mantém, ou se há diferenças significativas na percepção das pessoas sobre o tema. 


\section{Metodologia}

Diante das evidências apontadas no capítulo anterior, buscamos verificar se tais questões estão presentes nas sociedades brasileira e portuguesa, para isso, optamos por conduzir uma pesquisa fundamentada no modelo do Pew Research Center (PRC), da qual o Brasil havia participado em 2018. Nosso objetivo com tal abordagem foi verificar primeiramente se as tendências apontadas anteriormente não sofreram alterações neste espaço de tempo, ou quando incluídos grupos mais jovens no universo amostral. Em segundo lugar, se existem diferenças significativas na percepção de indivíduos do Brasil e de Portugal na apreciação do tema. Em terceiro, se entre nossos entrevistados, há diferenças na percepção entre homens e mulheres em relação ao risco da automação para o emprego, se o grau de instrução dos indivíduos impacta na percepção dos riscos, e, por fim, se os entrevistados apresentam algum indício de "fobia digital".

Apesar de pesquisas com amostras não probabilísticas estarem sujeitas a críticas porque nem todos os elementos da população tem a mesma probabilidade de serem selecionados, cada vez mais pesquisas por amostragem não probabilística têm sido utilizadas, por questões de agilidade, criatividade e, sobretudo, racionalidade em termos da relação custo-benefício. As amostras voluntárias ou por conveniência são aquelas que se disponibilizam voluntariamente para compor a amostra, em função da disponibilidade e acessibilidade dos elementos da população (Morais, 2005).

A transformação digital é um assunto amplo e complexo, pois existem muitos aspectos importantes e interessantes que merecem ser pesquisados. No entanto, para este estudo, as variáveis que procuramos colocar em foco foram: as perspectivas das pessoas em relação ao futuro e às mudanças no mercado de trabalho; o entendimento sobre a transformação digital; as expectativas em relação e o grau de reponsabilidade dos diferentes atores sociais na adequação às mudanças. Tal direcionamento nos permitiu analisar, não apenas as próprias questões colocadas, como as hipóteses antes levantadas.

Para obter estes dados de forma eficaz, optamos por realizar uma pesquisa quantitativa, método utilizado para medir opiniões, reações, sensações, hábitos e atitudes, por meio de uma amostra que represente de forma estatisticamente comprovada o universo a ser estudado (Manzato \& Santos, 2012). Neste sentido, decidimos usar parte de um questionário já existente que atendesse não somente aos nossos interesses de pesquisa, mas que também estivesse de acordo com as normas para elaboração de uma pesquisa quantitativa. O estudo publicado pelo PRC (Wike \& Stokes, 2018, September) atendia perfeitamente estes requisitos e, ao replicar um estudo de referência, evitamos a necessidade de efetuar pré-testes amostral e minimizamos chances de erros estruturais. Embora tenhamos 
adaptado o questionário e ampliado algumas questões que julgamos pertinentes ao tema, 0 nosso questionário é similar ao do PRC, o que nos permitiu comparar os resultados. $O$ questionário completo contém doze questões e pode ser visualizado no Apêndice deste artigo.

A pesquisa de campo foi realizada eletronicamente através do Google Forms e impulsionada nas redes sociais; também abrangeu alunos brasileiros do Centro Paula Souza, em São Paulo e alunos portugueses da Universidade do Minho, da cidade de Braga, no período de 10 de março de 2020 e 18 de maio de 2020. Neste intervalo, foi colhida a opinião de 420 entrevistados, contendo pessoas de 15 a 94 anos, residentes no Brasil e em Portugal. As características demográficas da amostra são apresentadas na Tabela 1.

Tabela 1. Caracterização da amostra do estudo

\begin{tabular}{lccc}
\hline & $\begin{array}{c}\text { Brasileiros } \\
(n=248)\end{array}$ & $\begin{array}{c}\text { Portugueses } \\
(n=172)\end{array}$ & $\begin{array}{c}\text { Total } \\
(n=420)\end{array}$ \\
\hline Sexo & 152 & 130 & 282 \\
Feminino & 96 & 42 & 138 \\
Masculino & & & \\
\hline Grau de escolaridade & 7 & -- & 7 \\
Fundamental incompleto & 144 & 59 & 203 \\
Médio incompleto & 3 & -- & 3 \\
Médio completo & 29 & 66 & 95 \\
Graduação incompleta & 12 & 2 & 14 \\
Graduação completa & 42 & 43 & 85 \\
Pós-graduação incompleta & 11 & 2 & 13 \\
Pós-graduação completa & & & \\
\hline Faixa etária & 115 & 44 & 159 \\
$15-19$ anos & 55 & 99 & 154 \\
$20-29$ anos & 37 & 17 & 54 \\
$30-39$ anos & 22 & 6 & 28 \\
$40-49$ anos & 19 & 6 & 25 \\
$\geq 50$ anos & & &
\end{tabular}

Conforme podemos observar na tabela acima, o perfil dos entrevistados é bastante heterogêneo, no entanto, podemos destacar uma maior participação das mulheres, dos jovens entre 15 e 19 anos, com nível de instrução de ensino médio incompleto. Tal preponderância se deve, principalmente, ao fato de a pesquisa ter tido mais adesão no ambiente escolar.

Cabe apresentar aqui também duas limitações relacionadas à metodologia utilizada. A primeira diz respeito ao tamanho da amostra, os 420 respondentes (248 brasileiros e 172 portugueses) não perfazem uma amostra estatisticamente representativa da população de 
nenhum dos dois países, além de ser uma amostragem por conveniência. Por esse motivo, o presente trabalho, bem como outros similares apresentados na seção anterior, oferece conclusões que se limitam ao próprio universo da mostra e abrir oportunidades de discussões a partir dos dados primários coletados. Uma segunda limitação diz respeito às perguntas realizadas, o objetivo do questionário aplicado foi explorar as percepções de brasileiros e portugueses acerca do potencial impacto da Indústria 4.0 sobre os trabalhadores. Assim, proposições sobre o que poderá ser feito com relação a esses impactos, apesar de reconhecidamente importantes, deverão ser objetos de estudos futuros.

\section{Resultados}

Procuramos extrair informações da base de dados que nos permitiram avaliar a percepção dos entrevistados em consonância com os trabalhos relacionados e as hipóteses que a pesquisa atual nos trouxe.

A primeira questão que analisaremos diz respeito justamente ao grau de conhecimento dos participantes sobre a quarta revolução industrial e a Indústria 4.0. Do total de participantes, $16 \%$ declaram não ter nenhum conhecimento sobre o tema, $36 \%$ alegam pouco conhecimento, 30\% assumem ter algum conhecimento, 15\% um bom conhecimento e apenas $2 \%$ afirmam ter muito conhecimento sobre o tema. No geral, $52 \%$ dos entrevistados desconhecem ou conhecem apenas superficialmente $o$ assunto.

Apresentamos na Tabela 2 a distribuição percentual das respostas a essa pergunta, de acordo com as características sociodemográficas dos respondentes. Podemos destacar que os brasileiros que possuem conhecimento sobre o tema somam 53\%, enquanto os portugueses $40 \%$. Essa diferença é explicada pela quantidade de portugueses que declararam não ter nenhum conhecimento sobre o tema (24\%), maior que entre os brasileiros (11\%). Outro destaque é a diferença entre as mulheres e os homens: $64 \%$ dos homens declaram conhecer pelo menos algo sobre o tema, enquanto $40 \%$ das mulheres declararam ter algum conhecimento; $22 \%$ das respondentes não possuem nenhum conhecimento sobre o tema, proporção que fica em $5 \%$ entre os homens.

Na segunda questão foi perguntado sobre quais áreas as pessoas consideravam que a adoção das novas tecnologias poderia afetar. Acerca disso, 55\% dos entrevistados consideraram que todas as áreas das empresas seriam afetadas, enquanto apenas $1 \%$ informou acreditar que nenhuma área da empresa seria afetada. 
A terceira questão busca entender o quanto as pessoas pensam que as novas tecnologias serão capazes de fazer grande parte do trabalho que hoje é feito por seres humanos. No geral, 44\% dos respondentes indicaram ter certeza de que isso irá ocorrer, 53\% consideram provável que isso ocorra e apenas 3\% acreditam que isso não acontecerá. Comparando as respostas por nacionalidade, $47 \%$ dos brasileiros têm certeza disso, já entre os portugueses, apenas $39 \%$ pensam da mesma maneira.

Tabela 2. Distribuição (em \%) das repostas à pergunta

"Qual seu grau de entendimento sobre o tema 'quarta revolução industrial' / 'Indústria 4.0'?"

\begin{tabular}{|c|c|c|c|c|c|c|}
\hline & Nenhum & Pouco & Algum & Bom & Muito & Total \\
\hline \multicolumn{7}{|l|}{ Nacionalidade } \\
\hline Brasileira & 11 & 36 & 33 & 18 & 2 & 100 \\
\hline Portuguesa & 24 & 35 & 26 & 12 & 3 & 100 \\
\hline \multicolumn{7}{|l|}{ Sexo } \\
\hline Feminino & 22 & 38 & 30 & 9 & 1 & 100 \\
\hline Masculino & 5 & 31 & 30 & 28 & 6 & 100 \\
\hline \multicolumn{7}{|l|}{ Grau de escolaridade } \\
\hline Fundamental incompleto & 14 & 29 & 43 & 14 & 0 & 100 \\
\hline Médio incompleto & 20 & 43 & 23 & 14 & 0 & 100 \\
\hline Médio completo & 33 & 66 & 0 & 0 & 2 & 100 \\
\hline Graduação incompleta & 19 & 29 & 39 & 11 & 7 & 100 \\
\hline Graduação completa & 7 & 29 & 43 & 14 & 7 & 100 \\
\hline Pós-graduação incompleta & 9 & 28 & 33 & 22 & 7 & 100 \\
\hline Pós-graduação completa & 0 & 31 & 31 & 38 & 0 & 100 \\
\hline \multicolumn{7}{|l|}{ Faixa Etária } \\
\hline $15-19$ anos & 17 & 47 & 23 & 13 & 1 & 100 \\
\hline $20-29$ anos & 21 & 30 & 35 & 12 & 2 & 100 \\
\hline $30-39$ anos & 7 & 35 & 28 & 24 & 6 & 100 \\
\hline $40-49$ anos & 18 & 25 & 29 & 25 & 4 & 100 \\
\hline$\geq 50$ anos & 4 & 20 & 48 & 20 & 8 & 100 \\
\hline
\end{tabular}

Na figura 1 destacamos o fato de que, à medida que aumenta a faixa etária, aumenta também a expectativa de que as novas tecnologias poderão fazer grande parte do trabalho que hoje é feito por humanos. A maioria dos indivíduos acima dos 40 anos tem certeza de que isso poderá acontecer. 
Figura 1: Respostas à questão Q3 distribuídas por faixa etária

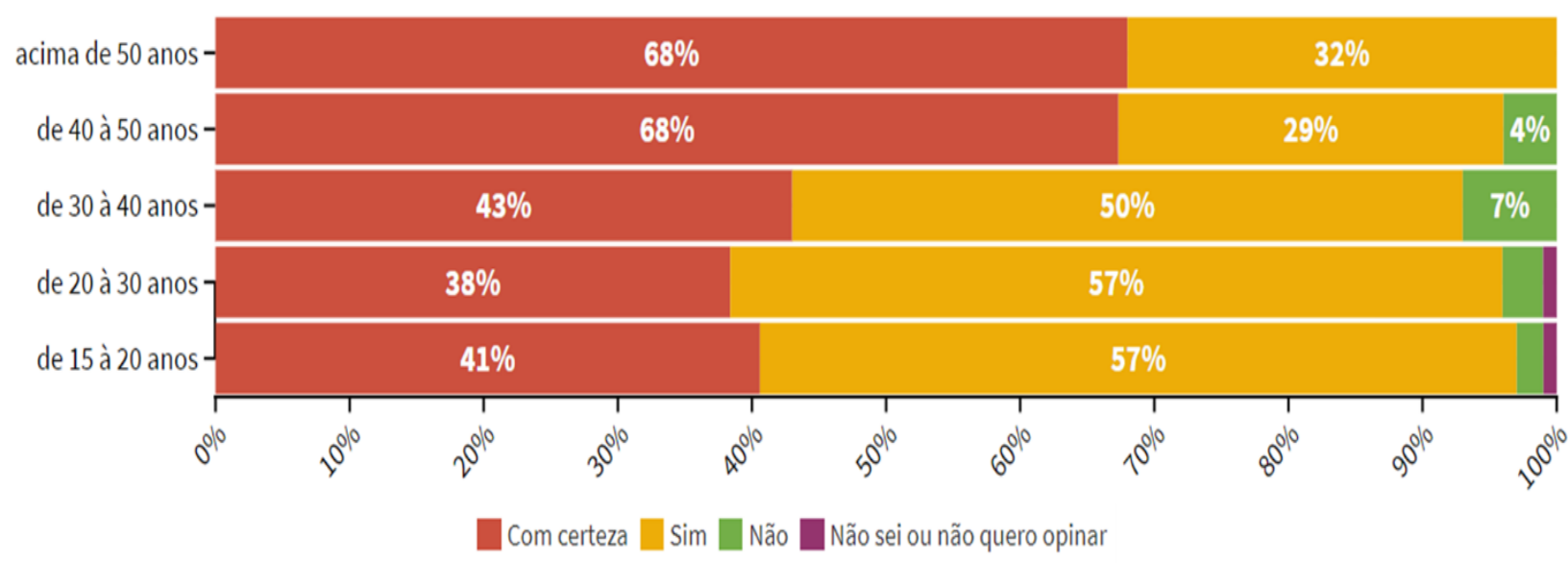

$\mathrm{Na}$ quarta pergunta o intuito era saber se os entrevistados imaginam que seriam criados novos empregos melhor remunerados com as novas tecnologias. Quase metade dos entrevistados (49\%) considera que não existirão novos empregos nem melhor remuneração, enquanto $36 \%$ acreditam que sim. Não houve diferença significativa entre os brasileiros e portugueses nesse aspecto.

A quinta pergunta do questionário buscou entender se os entrevistados acham que as pessoas com baixa qualificação teriam dificuldade para conseguir emprego num mundo altamente tecnológico. Nessa questão não foram observadas diferenças significativas entre as duas nacionalidades, mas podemos perceber, como indicado pela Figura 2, que, embora no geral a apreensão seja alta em ambos os grupos, as mulheres são mais pessimistas que os homens (94\% contra $88 \%$ ) quanto à empregabilidade da mão de obra com baixa qualificação.

Figura 2: Respostas à questão Q5 distribuídas por sexo
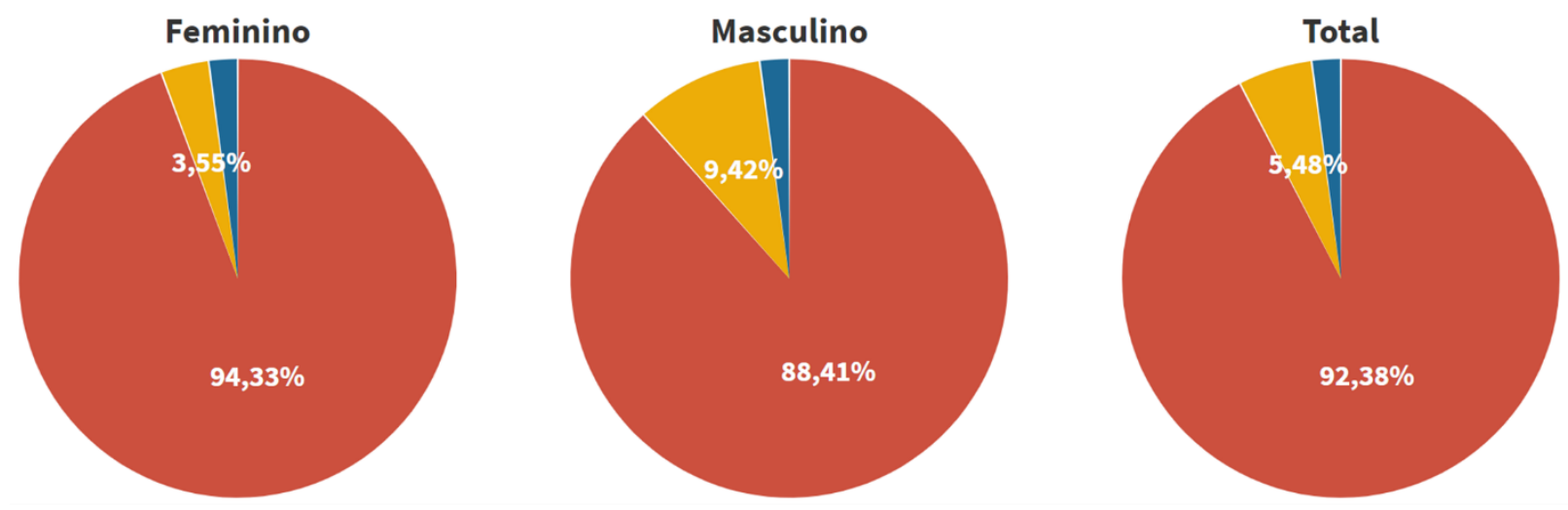

Sim $\square$ Não $\square$ Não sei/Não quero opinar 
Na sexta pergunta procuramos entender se os entrevistados notam que haveria melhoria na eficiência econômica com as novas tecnologias. Os resultados revelam que, de forma geral, as repostas estão bem divididas quanto à essa possibilidade, com 34\% acreditando que a economia não seria mais eficiente, $35 \%$ que seria e $31 \%$ não sabem responder ou preferem não opinar. Os brasileiros demonstraram maior pessimismo quanto à concretização dessa possibilidade, dos participantes, 38\% afirmam que isso não ocorreria e $33 \%$ que ocorreria. Já dentre os portugueses, 29\% não acreditam que a economia melhoraria e $38 \%$ acreditam que isso pode ocorrer.

Ao cruzar as respostas desta questão com as da primeira questão percebe-se que, quanto maior o grau de conhecimento (entendimento), maior a porcentagem de indivíduos que acreditam que a transformação digital aumentará a eficiência da economia (Figura 3).

Figura 3: Cruzamento das respostas dadas às questões Q1 e Q6

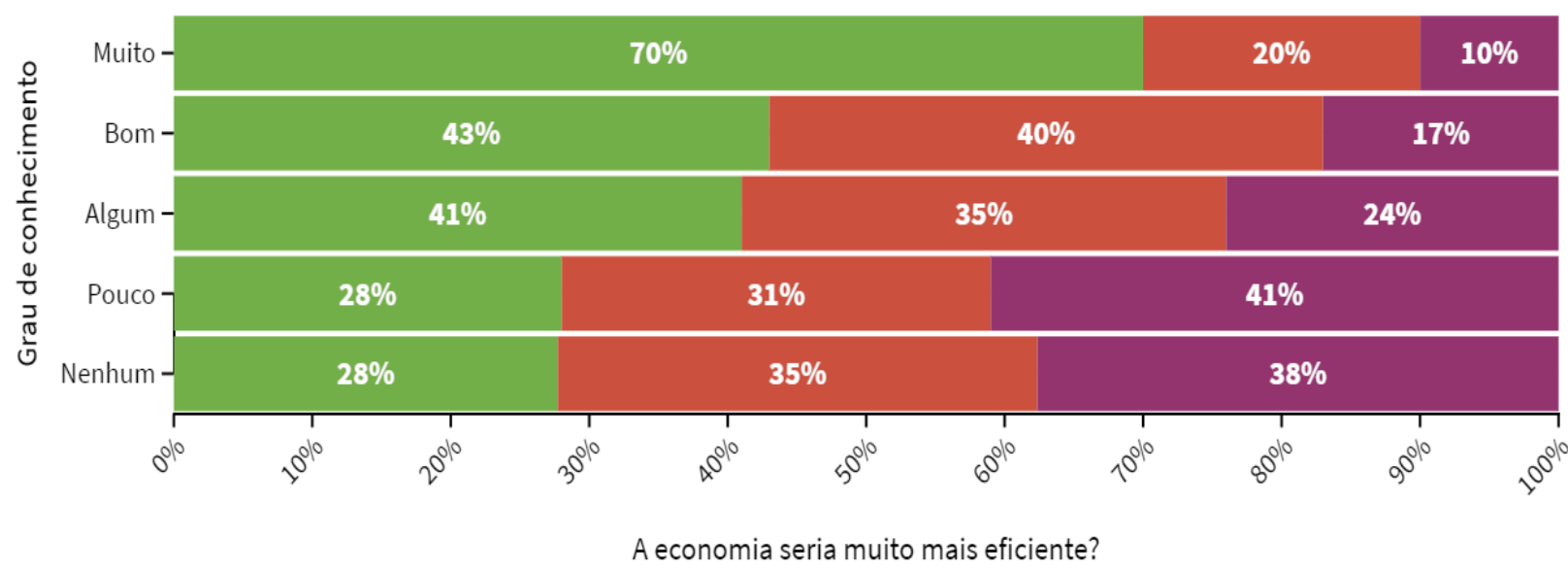

Sim $\square$ Não $\square$ Não sei ou não quero responder

A sétima pergunta buscou entender qual a probabilidade de que a profissão exercida atualmente pelos respondentes (ou que estão estudando para exercê-la) seja totalmente feita por máquinas no futuro. Apenas $4 \%$ dos respondentes têm certeza de que suas profissões serão totalmente feitas por máquinas, $25 \%$ acreditam que há grande probabilidade de serem substituídos por máquinas, enquanto $55 \%$ consideram haver pouca perspectiva de isso ocorrer e $14 \%$, nenhuma possibilidade. Comparando as nacionalidades, $33 \%$ dos brasileiros acreditam haver grande probabilidade, enquanto a porcentagem cai para $13 \%$ dentre os portugueses. Por outro lado, $19 \%$ dos portugueses acreditam que não haja nenhuma probabilidade de serem substituídos totalmente por máquinas no trabalho, proporção que cai para $10 \%$ dentre os brasileiros. 
Nessa questão, a correlação com o grau de conhecimento sobre transformação digital revela que, dentre as pessoas com muito ou bom grau de conhecimento sobre o tema, $3 \%$ têm certeza de que terão seus trabalhos totalmente substituídos por máquinas e 36\% acreditam que a probabilidade de que isso ocorra seja alta. Já, dentre aqueles que não têm nenhum ou têm pouco conhecimento sobre o tema, esses percentuais caem para $5 \%$ e $20 \%$, respectivamente.

Ao discutir os desafios trazidos pelas mudanças tecnológicas, um ponto importante é avaliar o processo de transição para esta nova realidade, saber se a sociedade está se preparando adequadamente para o futuro é fundamental para avaliar os acontecimentos e propor soluções. Na oitava pergunta do questionário, os respondentes afirmam, em sua grande maioria, estarem se preparando razoavelmente (35\%), suficientemente bem (39\%) ou totalmente $(12 \%)$ para enfrentar as mudanças.

Dois destaques podem ser dados aqui, o primeiro, com relação à faixa etária, mostrando que $86 \%$ dos indivíduos da faixa dos 15 aos 20 anos sentem que estão se preparando, pelo menos razoavelmente, para o futuro; enquanto na última faixa etária, dos 50 anos ou mais, a porcentagem cai para $72 \%$. O segundo destaque é com relação ao grau de escolaridade que mostra que $86 \%$ dos indivíduos, com ensino fundamental incompleto, sentem que estão se preparando pelo menos suficientemente bem; valor superior ao apresentado por aqueles com graduação completa (56\%), pós-graduação incompleta (46\%) e completa (50\%).

Figura 4: Cruzamento das respostas dadas às questões Q7 e Q8

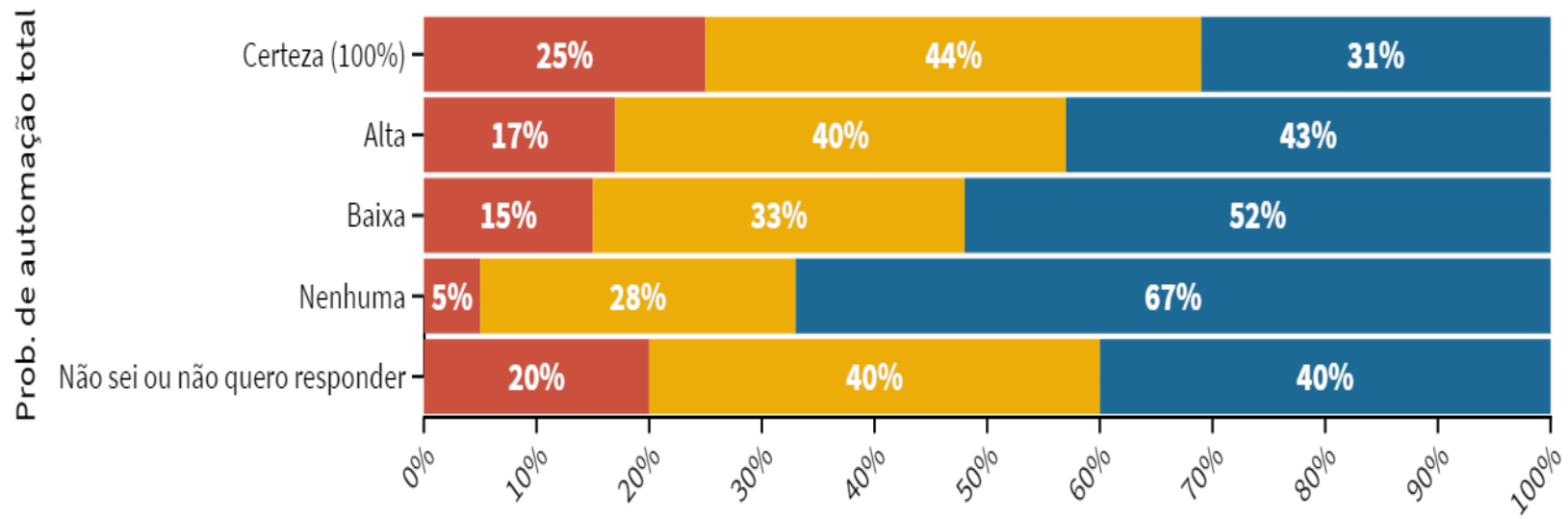

Preparo para o mercado de trabalho do futuro

nem um pouco ou pouco $\square$ razoavelmente $\square$ suficientemente ou totalmente 
O cruzamento das respostas à oitava questão com as da sétima nos mostra um interessante resultado. Quanto maior a certeza dos indivíduos com relação à automação de sua profissão, menos o indivíduo declara se sentir preparado para o mercado de trabalho do futuro, como mostra a Figura 4.

As quatro questões seguintes de nosso inquérito (Q9-Q12) tinham por objetivo detectar o nível de reponsabilidade dos indivíduos, governos, escolas e empresas na garantia de que o profissional desenvolva as habilidades e educação necessárias para ser bem-sucedido no futuro. Como demonstram os gráficos da Figura 5, os respondentes acreditam que todos esses grupos teriam muita ou alguma responsabilidade. O único grupo que se destaca dos demais é o representado pelas empresas, que para apenas $52 \%$ dos respondentes teria muita responsabilidade, enquanto em todos os outros grupos essa proporção chega a, pelo menos, 70\%. De qualquer forma, considerando muita ou alguma responsabilidade, as empresas atingem o patamar de mais de $90 \%$, o mesmo ocorre com todos os grupos.

Figura 5: Respostas dadas às questões Q9, Q10, Q11 e Q12
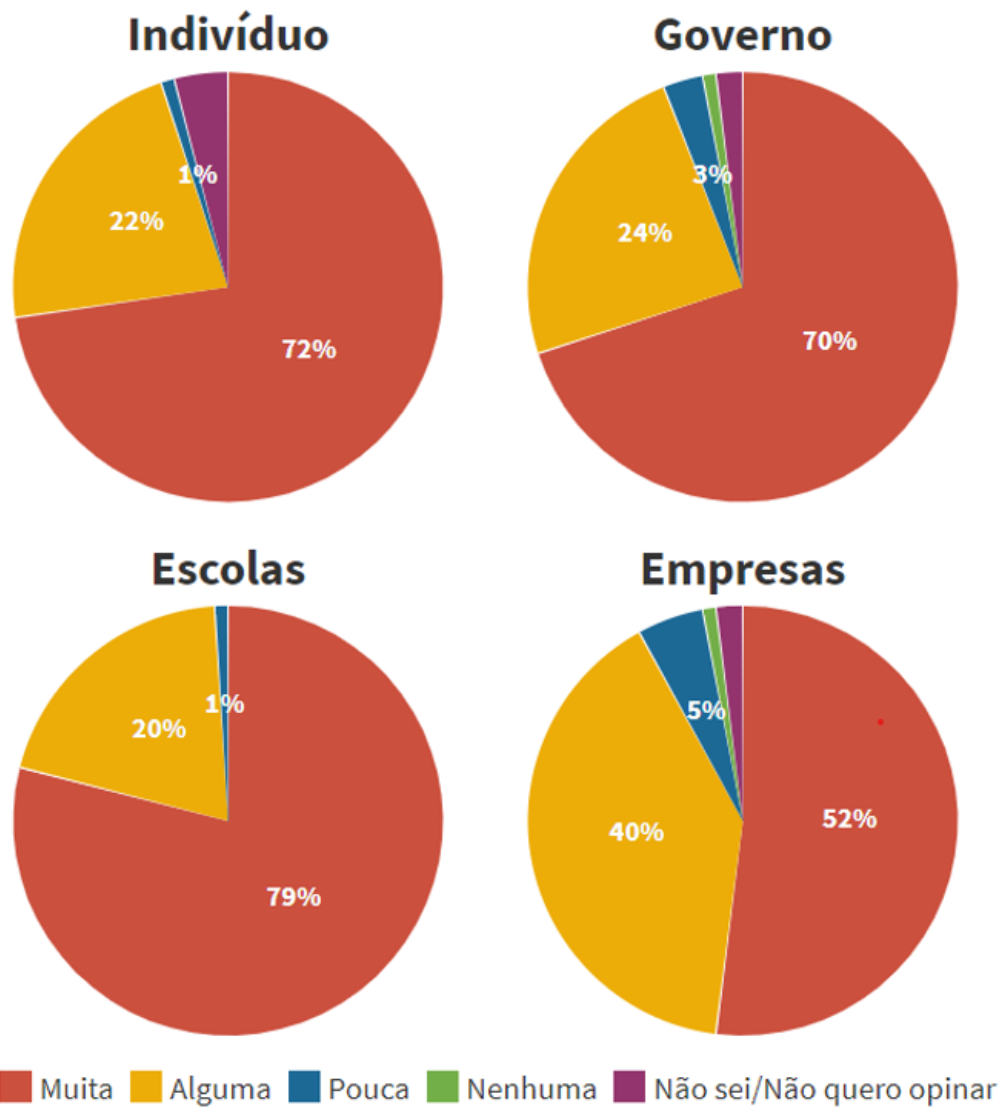
Ao compararmos as respostas por nacionalidade, podemos destacar que $76 \%$ dos brasileiros e $67 \%$ dos portugueses consideram que os indivíduos teriam muita responsabilidade. Com relação à responsabilidade que os governos teriam, $73 \%$ dos brasileiros e $65 \%$ dos portugueses consideram que seria muita responsabilidade.

\section{Discussão}

A base de dados da qual extraímos estas análises permite diversas observações e perspectivas, procuramos aqui focar aquelas que estão mais alinhadas aos objetivos centrais deste estudo, no intuito de detectar se existe algum tipo de "fobia digital" entre os entrevistados, além de avaliar a expectativa das pessoas em relação aos possíveis impactos da quarta revolução industrial e da Indústria 4.0 em suas vidas e quais sentimentos e reações essas mudanças causam.

Um fato notório neste estudo é o baixo grau de entendimento das pessoas em relação às novas tecnologias, conforme podemos observar, mais da metade dos entrevistados (52\%) desconhecem ou conhecem apenas superficialmente o tema, com destaque para as mulheres e para os portugueses. Mesmo entre os mais jovens, muitos disseram nunca ter ouvido falar ou não saber bem do que se tratam estas mudanças.

Se levarmos em conta o potencial de automação das atividades nas próximas décadas, a projeção para o mercado brasileiro é de $60 \%$ segundo Lima et al. (2021) e 55\% segundo Albuquerque et al. (2019), e de 52\% para o mercado português (Duarte, 2019). Tais resultados reforçam a importância e a necessidade de mais pessoas e instituições dedicarem esforços em estudar e divulgar este fenômeno, pois, apesar da grande importância, o assunto ainda é pouco debatido na sociedade como um todo, e, conforme aponta McClure (2018), o desconhecimento acerca das novas tecnologias está diretamente relacionado ao medo ou à "tecnofobia". Assim, a educação sobre a transformação digital é um instrumento fundamental para a construção de um sistema produtivo mais moderno.

Dentre as pessoas que declararam maior grau de entendimento acerca do tema, podemos destacar os homens, as pessoas mais velhas e aquelas com maior grau de instrução. Esta última constatação também é verificada em Acemoglu (2002), Acemoglu e Autor (2011), Autor, Levy e Murnane (2003), Dekker, Salomons e van der Waal (2017), Dodel e Mesch (2020), McClure (2018), e Morikawa (2017), cujos estudos revelam que o maior grau de instrução está relacionado com uma postura mais positiva acerca das mudanças.

Embora afirmem conhecer pouco sobre os assuntos, os entrevistados foram bastante coerentes ao avaliar os possíveis impactos destas transformações, ao serem questionados sobre quais as áreas de trabalho eles percebem que serão mais impactadas 
pelas novas tecnologias, $55 \%$ dos entrevistados acreditam que as mudanças decorrentes da transformação digital deverão afetar todas as áreas da empresa, do chão de fábrica ao alto escalão. Estes resultados estão alinhados ao de Kaplan e Haenlein (2019), no qual afirmam que máquinas, robôs e sistemas de IA, podem substituir, desde atividades rotineiras, até atividades que requeiram capacidade cognitiva mais aperfeiçoada.

Ao tratar da probabilidade da substituição da mão de obra humana por máquinas, a maioria dos entrevistados admitem que isso poderá ocorrer nos próximos 50 anos. Para $44 \%$ dos entrevistados, seguramente, isso irá acontecer, e para 53\% isso tem grandes chances de ocorrer. Essa certeza é menor entre os portugueses do que entre os brasileiros (39\% contra 47\%). Os resultados da pesquisa de Wike e Stokes (2018, September) também seguem essa linha, demonstrando que a maioria dos entrevistados acreditava que as máquinas iriam substituir muito do trabalho que hoje é realizado por humanos. No entanto, nossos resultados mostram uma diferença significativa dos apresentados na pesquisa anterior, na qual apenas $18 \%$ dos brasileiros afirmavam ter certeza das mudanças; por outro lado, os que não acreditavam em tais mudanças eram $10 \%$, hoje somam apenas $3 \%$. Os resultados nos levam a concluir que a expectativa das pessoas em relação ao potencial das novas tecnologias sofreu alterações nos últimos anos.

Entre as preocupações mais comuns com as transformações em curso, está a questão da empregabilidade. Para a metade dos entrevistados (49\%), independentemente de qualquer outra variável analisada, a adoção das novas tecnologias não induz a criação de novos empregos, nem melhoria salarial, enquanto um terço da amostra (36\%) afirma que as inovações digitais podem trazer novas oportunidades de emprego e melhores remunerações. Estes resultados mantêm certo alinhamento com aqueles obtidos por Wike e Stokes (2018, September), que indicaram que a maioria dos brasileiros (58\%) não acreditava em novos empregos e melhores salários. Dekker, Salomons e van der Waal (2017) demonstraram em seus estudos que, em países onde a taxa de desemprego é alta e os sindicatos são maios fracos, há maior medo dos robôs no trabalho. Entretanto, nossos resultados não apontam diferenças significativas entre a visão dos brasileiros e a dos portugueses com relação à possibilidade de criação de novos e melhores empregos, como resultado da quarta revolução industrial. Os entrevistados das duas nacionalidades demonstraram ser igualmente descrentes com relação a essa possibilidade.

Procuramos também verificar a opinião das pessoas sobre a probabilidade de indivíduos com baixa qualificação arrumarem emprego em um mundo tecnológico: 92\% acreditam que quem tem pouca instrução deverá enfrentar dificuldades para conseguir emprego, na Indústria 4.0; entre os poucos que não acreditam em tais dificuldades (5\%), a grande maioria é composta por homens. 
Nossos resultados, quando comparados aos de Wike e Stokes (2018, September), mostram uma proporção 9 pontos percentuais maior em 2020. Essa preocupação ressoa também no estudo de Dodel e Mesch (2020), no qual os trabalhadores que desenvolviam tarefas manuais ou físicas demonstraram maior medo com relação ao impacto das novas tecnologias. O estudo de McClure (2018) também reconhece uma maior "tecnofobia" dentre as pessoas com menor escolaridade, as que tendem a ocupar postos de trabalho que exigem tarefas manuais, mais fáceis de serem automatizadas.

A possibilidade das pessoas com menor grau de escolaridade serem mais impactadas pelas novas tecnologias - em particular, a automação - foi levantada também por estudos focados em estimar probabilidades de substituição de trabalhadores (Frey \& Osborne, 2017; Lima et al., 2021). Em particular, para o caso brasileiro, o índice de automação para os trabalhadores com ensino superior incompleto seria de $68 \%$, enquanto para aquelas com o ensino superior completo esse índice cai para 37\% (Lima et al., 2021).

Outra questão levantada foi a expectativa das pessoas em relação à melhoria da eficiência econômica frente às novas tecnologias. Se analisarmos isoladamente a questão, podemos afirmar que há uma grande incerteza quanto ao impacto positivo das novas tecnologias sobre a eficiência econômica, dado o equilíbrio entre os que acreditam nesse resultado, os que não acreditam e os que não sabem responder.

Porém, ao cruzarmos essa questão com o quanto os entrevistados conhecem sobre a transformação digital (Figura 3) percebemos que quanto maior o grau de entendimento do entrevistado sobre o tema, maior é a percepção de que haveria melhoria da eficiência econômica. Aqui, também encontramos um alinhamento dos nossos resultados com os de McClure (2018) que relaciona um maior desconhecimento sobre as novas tecnologias com uma maior "tecnofobia".

Se, no âmbito geral, não há muito otimismo em relação a emprego, renda e melhoria econômica, do ponto de vista individual a percepção muda. Ao serem indagados se as profissões que os entrevistados exercem hoje ou virão a exercer no futuro podem vir a ser totalmente feitas por máquinas, robôs ou IA, 55\% acreditam que a chance de as novas tecnologias "roubarem" seu emprego é baixa. Os resultados parecem corroborar com a teoria de Hainguerlot, Vergnaud e Gardelle (2018), pois quando verificamos o grau de confiança dos indivíduos que possuem maior conhecimento acerca do assunto, percebemos que estes se sentem mais propensos a perder seus postos para a automação, enquanto os "leigos" sentemse menos ameaçados.

Conforme vimos na questão 8 , a grande maioria das pessoas ( $85 \%$ ) acredita estar se qualificando de maneira razoável para o mercado de trabalho do futuro. Podemos destacar 
os $86 \%$ dos jovens que não concluíram o ensino fundamental, porém possuem grande segurança de que estão no caminho certo para enfrentar os desafios futuros. Embora pareça um contrassenso, já que 53\% dos entrevistados acham que as novas tecnologias podem vir a substituir o trabalho humano, esse "otimismo" ou "confiança" podem ser explicados por Hainguerlot, Vergnaud, e de Gardelle (2018) e Briel et al. (2020): se os jovens são os mais seguros em relação ao futuro e, ainda, os que menos afirmam conhecer sobre o tema, podemos supor que, na falta de conhecimento específico, eles estão se baseando apenas no seu grau de confiança sobre o futuro e em si mesmos.

Os desafios trazidos pelas novas tecnologias são muitos. Cabe à sociedade como um todo, aos indivíduos, aos governos, às escolas e às empresas garantir que as pessoas desenvolvam novas habilidades e tenham acesso à educação necessária para serem bemsucedidas no futuro. Para os entrevistados, todos os atores sociais elencados têm grande responsabilidade nesse processo, acreditando que a iniciativa privada seja o setor ao qual se atribui menor reponsabilidade, enquanto as escolas são consideradas as maiores responsáveis por tal adequação (79\% atribuem muita responsabilidade a ela, e nenhum participante acredita que as escolas não tenham nenhuma responsabilidade quanto a isso).

Comparando nossos resultados com os de Wike e Stokes (2018, September), não verificamos grandes divergências, prevalece a ideia de que os indivíduos são os maiores responsáveis em se qualificar para enfrentar as mudanças, seguidos pelos governos e pelas escolas, sendo recorrente a ideia de que a iniciativa privada tem menos propensão a contribuir no enfrentamento desse desafio do que os demais.

Apesar disso, é importante destacar que quase todos os respondentes consideraram que indivíduos, governos, escolas e empresas têm muita ou alguma responsabilidade em garantir que o profissional tenha as habilidades e educação necessárias para ser bem-sucedido no futuro. Isso ressoa em outras pesquisas sobre o tema que buscam descrever o que cada um desses atores sociais poderia fazer na adequação da força de trabalho às novas tecnologias (Lima et al., 2021; McKinsey Global Institute, 2017). As empresas poderiam introduzir tecnologias para ampliar as habilidades dos trabalhadores (em vez de substituí-los totalmente por máquinas) e oferecer cursos de requalificação para seus trabalhadores aprenderem a lidar com as novas tecnologias. Os governos, por sua vez, poderiam implementar políticas públicas de redução de carga horária e compartilhamento de postos de trabalho em setores mais críticos, rever a política tributária para melhor balancear a equação trabalho x capital, e ainda modificar os sistemas de proteção aos trabalhadores desempregados para não só suportar os cidadãos durante o desemprego, mas, permitir que sejam capazes de se requalificar tecnologicamente. As instituições de ensino têm um papel importante no acompanhamento das mudanças no mercado de trabalho para analisar e alterar 
seus portfólios de cursos e as próprias grades curriculares de acordo com as demandas tecnológicas atuais e futuras do mercado de trabalho. Por fim, caberia aos indivíduos entender que os bons empregos exigirão cada vez mais uma aprendizagem contínua ao longo da vida; e, a partir de informações sobre mudanças tecnológicas, identificar as demandas por habilidades técnicas avançadas e por habilidades socioemocionais, ainda dificilmente substituíveis pelas máquinas inteligentes.

\section{Conclusão}

Os resultados observados, tanto em nossa pesquisa como nas demais analisadas, revelam que, independentemente de variáveis socioeconômicas, nacionalidade ou outras características pessoais, há um consenso sobre os potenciais impactos das novas tecnologias na vida das pessoas e para o futuro do trabalho. Embora não houvesse uma pergunta explícita sobre "medo" em nosso questionário, diversas observações apontam que a "fobia digital" é relevante para uma parcela significativa dos entrevistados, principalmente no que tange à empregabilidade. Entre os dados que corroboram para evidenciar tal fobia, podemos destacar que $55 \%$ dos entrevistados acreditam que a adoção de novas tecnologias pode afetar todas as áreas da empresa; para $97 \%$ as novas tecnologias podem substituir a mão de obra humana em grande parte dos trabalhos; $49 \%$ não acreditam na criação de novos empregos ou melhor remuneração em decorrência da adoção de mais tecnologias no ambiente de trabalho; além disso, $92 \%$ dos entrevistados afirmam que pessoas com baixa qualificação deverão ter mais dificuldades para arranjar emprego no futuro.

Conforme apontou McClure (2018), as pessoas temem que as novas tecnologias possam roubar seus empregos e trazer problemas financeiros. Já Dodel e Mesch (2020) apontam que as novas tecnologias podem gerar ansiedades sociais, e que essas ansiedades são mais acentuadas entre os segmentos mais vulneráveis da sociedade. Porém, nossos resultados - assim como os de Acemoglu e Autor (2011), Autor, Levy e Murnane (2003), Dekker, Salomons e van der Waal (2017), Dodel e Mesch (2020), McClure (2018), Morikawa (2017) - apontam que quanto maior o grau de instrução e o conhecimento sobre o assunto, menor é a expectativa de perder o próprio emprego para as novas tecnologias, e, portanto, menor é a "fobia digital".

Se as previsões de Albuquerque et al. (2019), Lima et al. (2019), Lima et al. (2021) e Duarte (2019) se confirmarem, tanto Brasil quanto Portugal terão de buscar mecanismos para enfrentar a transformação digital e garantir que o processo traga o menor impacto negativo possível ao conjunto da força de trabalho.

Uma das formas de enfrentar a "fobia digital" é investir na formação, no esclarecimento e na qualificação das pessoas. De acordo com nossos entrevistados, essa é 
uma responsabilidade que cabe a todos. Se quisermos que a quarta revolução industrial traga mais benefícios que malefícios, e que a sociedade tenha acesso aos ganhos de produtividade conferidos pela Indústria 4.0, é necessário que os indivíduos busquem se qualificar e aprimorar suas habilidades, e que governos, escolas e a iniciativa privada promovam uma transição planejada, que garanta às pessoas o acesso a estas oportunidades, além de mecanismos para proteger as que não consigam se adequar.

Estudar como as transformações digitais irão afetar o futuro do trabalho é uma tarefa importante, para que possamos entender e ajudar a sociedade a lidar com as mudanças em curso. Este artigo é uma pequena contribuição, que pode abrir caminhos para novas abordagens. Novos estudos podem complementar e ampliar a discussão sobre quais medidas concretas os governos, escolas, empresas e indivíduos devem tomar para fazer que a quarta revolução industrial seja uma revolução inclusiva e sustentável. No caso da pesquisa apresentada neste artigo, tivemos como respondentes um número limitado de profissionais e estudantes. Certamente, outras pesquisas podem coletar dados primários de outros grupos sociais, como gestores de instituições de ensino, administradores de empresas e servidores públicos de diferentes órgãos governamentais. Por fim, seria interessante também entender o impacto da automação sobre outros segmentos da sociedade e examinar percepções sobre outras questões, como o aumento da desigualdade econômica.

\section{Referências}

Acemoglu, D. (2002). Technical change, inequality, and the labor market. Journal of Economic Literature, 40(1), 7-72. https://www.aeaweb.org/articles?id=10.1257/0022051026976

Acemoglu, D., \& Autor, D. (2011). Skills, tasks and technologies: implications for employment and earnings. In D. Card \& O. Ashenfelter (Eds.), Handbook of labor economics (Vol. 4, pp. 1043-1171). Elsevier. https://doi.org/10.1016/S0169-7218(11)02410-5

Albuquerque, P. H., Saavedra, C. A. P. B., de Morais, R. L., Alves, P. F., \& Peng, Y. (2019). Na era das máquinas, o emprego é de quem? Estimação da probabilidade de automação de ocupações no Brasil [Texto para Discussão, No. 2457], Instituto de Pesquisa Econômica Aplicada. https://www.ipea.gov.br/portal/images/stories/PDFs/TDs/190329 td 2457.pdf

Amorim, J. E. B. de. (2017). A "Indústria 4.0" e a sustentabilidade do modelo de financiamento do regime geral da segurança social. Cadernos de Dereito Actual, (5), 243-254. http://www.cadernosdedereitoactual.es/ojs/index.php/cadernos/article/view/132

Autor, D. H. (2015). Why are there still so many jobs? The history and future of workplace automation. Journal of Economic Perspectives, 29(3), 3-30. https://doi.org/10.1257/jep.29.3.3

Autor, D. H., Levy, F., \& Murnane, R. J. (2003). The skill content of recent technological change: an empirical exploration. The Quarterly Journal of Economics, 118(4), 1279-1333. https://doi.org/10.1162/003355303322552801 
Blit, J. (2020). Automation and reallocation: will COVID-19 usher in the future of work? Canadian Public Policy, 46(S2), S192-S202. https://doi.org/10.3138/cpp.2020-065

Briel, S., Osikominu, A., Pfeifer, G., Reutter, M., \& Satlukal, S. (2020). Overconfidence and gender differences in wage expectations. [SSRN Scholarly Paper ID 3661437], Social Science Research Network. https://papers.ssrn.com/abstract $=3661437$

Chernoff, A., \& Warman, C. (2020). COVID-19 and implications for automation. [NBER Working Series, No. w27249], National Bureau of Economic Research, Cambridge, MA. https://doi.org/10.3386/w27249

Confederanção Nacional da Indústria (CNI) (2016). Desafios para Indústria 4.0 no Brasil. https://www.portaldaindustria.com.br/publicacoes/2016/8/desafios-para-industria-40-nobrasil/

Dekker, F., Salomons, A., \& van der Waal, J. (2017). Fear of robots at work: the role of economic self-interest. Socio-Economic Review, 15(3), 539-562. https://doi.org/10.1093/ser/mwx005

Ding, L., \& Molina, J. S. (2020). "Forced automation" by COVID-19? Early trends from current population survey data. [Community Affairs Discussion Paper 88713], Federal Reserve Bank of Philadelphia. https://www.philadelphiafed.org/community-development/workforce-andeconomic-development/forced-automation-by-covid-19

Dodel, M., \& Mesch, G. S. (2020). Perceptions about the impact of automation in the workplace. Information, Communication \& Society, 23(5), 665-680. https://doi.org/10.1080/1369118X.2020.1716043

Duarte, J. B. (Coord.) (2019). Automação e futuro do emprego em Portugal: O imperativo da requalificação. Nova School of Business and Economics; Confederação Empresarial de Portugal (CIP). https://cip.org.pt/wp-content/uploads/2019/10/Relat\%C3\%B3rio-FoW NSBE-CIP.pdf

Frey, C. B., \& Osborne, M. A. (2017). The future of employment: how susceptible are jobs to computerisation? Technological Forecasting and Social Change, (114), 254-280. https://doi.org/10.1016/j.techfore.2016.08.019

Hainguerlot, M., Vergnaud, J.-C., \& de Gardelle, V. (2018). Metacognitive ability predicts learning cue-stimulus associations in the absence of external feedback. Scientific Reports, 8, 5602. https://doi.org/10.1038/s41598-018-23936-9

Heidhues, P., Kőszegi, B., \& Strack, P. (2018). Unrealistic expectations and misguided learning. Econometrica, 86(4), 1159-1214. https://doi.org/10.3982/ECTA14084

Hobsbawm, E. (2000). Da revolução industrial inglesa ao imperialismo (5a ed.). Forense Universitária.

Ivanov, S., Kuyumdzhiev, M., \& Webster, C. (2020, April 18). Automation fears: drivers and solutions. [SocArXiv Papers]. https://doi.org/10.31235/osf.io/jze3u

Lima, Y., Strauch, J., Esteves, M. G., \& Souza, J. M. de (2021). Exploring the future impact of automation in Brazil. Employee Relations, 43(15), 1052-1066. https://doi.org/10.1108/ER$\underline{08-2020-0364}$ 
Lima, Y., Strauch, J., Esteves, M. G., Souza, J. M. de, Chaves, M., \& Gomes, D. (2019). O futuro do emprego no Brasil: estimando o impacto da automação. Laboratório do Futuro - UFRJ. http://labfuturo.cos.ufrj.br/wp-content/uploads/2019/08/O-impacto-daautoma\%C3\%A7\%C3\%A3o-no-Brasil.pdf

Manzato, A. J., \& Santos, A. B. (2012). A elaboração de questionários na pesquisa quantitativa. [Material didático], Departamento de Ciência de Computação e Estatística, IBILCE, UNESP. http://www.inf.ufsc.br/ vera.carmo/Ensino 2012 1/ELABORACAO QUESTIONARIOS PESQ UISA QUANTITATIVA.pdf

Marray, K., Krishna, N., \& Tang, J. (2020). How do expectations affect learning about fundamentals? Some experimental evidence. [SSRN Scholarly Paper ID 3542787], Social Science Research Network. https://doi.org/10.2139/ssrn.3542787

McClure, P. K. (2018). "You're fired", says the robot: the rise of automation in the workplace, technophobes, and fears of unemployment. Social Science Computer Review, 36(2), 139-156. https://doi.org/10.1177/0894439317698637

McKinsey Global Institute (MGI) (2017). A future that works: Automation, employment, and productivity. Edited by J. Manyika, M. Chui, M. Miremadi, J. Bughin et al. https://www.mckinsey.com/ /media/mckinsey/featured\%20insights/Digital\%20Disruption/ Harnessing $\% 20$ automation $\% 20$ for $\% 20 a \% 20$ future $\% 20$ that $\% 20$ works/MGI-A-future-thatworks-Full-report.ashx

McKinsey Global Institute (MGI) (2020, September). What 800 executives envision for the pandemic workforce. https://www.mckinsey.com/featured-insights/future-of-work/what800-executives-envision-for-the-postpandemic-workforce

Morais, C. (2005). Escalas de medida, estatística descritiva e inferência estatística. [ESE Working Papers], Escola Superior de Educação, Bragança, Portugal. https://bibliotecadigital.ipb.pt/handle/10198/7325

Morikawa, M. (2017). Who are afraid of losing their jobs to artificial intelligence and robots? Evidence from a survey. [GLO Discussion Paper, No. 71], Global Labour Organization, Maastricht. https://www.econstor.eu/bitstream/10419/158005/1/GLO DP 0071.pdf

Oliveira, E. M. (2004). Transformações no mundo do trabalho, da revolução industrial aos nossos dias. Caminhos de Geografia, 5(11), 84-96. http://www.seer.ufu.br/index.php/caminhosdegeografia/article/view/15327

Wike, R., \& Stokes, B. (2018, September). In advanced and emerging economies alike, worries about job automation. Pew Research Center. https://www.pewresearch.org/global/wpcontent/uploads/sites/2/2018/09/Pew-Research-Center In-Advanced-and-Emerging-

Economies-Alike-Worries-about-Job-Automation 2018-09-13.pdf

World Economic Forum (WEF) (2020). Future of Jobs Report 2020. http://www3.weforum.org/docs/WEF Future of Jobs 2020.pdf 


\section{Apêndice: Questionário}

\section{Dados Socioeconômicos}

Sexo: ( ) Feminino; ( ) Masculino.

Idade: anos.

Nacionalidade: ( ) Brasileira; ( ) Portuguesa

Escolaridade: ( ) Fundamental / Básico; ( ) Médio / Secundário; ( ) Superior / Graduação;

( ) Pós-graduação / Mestrado / Doutorado

\section{Questões}

Q1. Qual seu grau de entendimento sobre o tema "quarta revolução industrial" / "Indústria 4.0"?

( ) Nenhum; ( ) Pouco; ( ) Algum; ( ) Bom; ( ) Muito.

Q2. Em seu entendimento, se as empresas adotarem novas tecnologias, como robótica, inteligência artificial, entre outras, isso poderá afetar quais áreas de trabalho dentro destas empresas?

( ) todas as áreas da empresa (alto, médio e baixo escalão);

( ) apenas as áreas intermediárias e operacionais (médio e baixo escalão);

( ) apenas a área operacional (produção, atendimento, prestação de serviços);

( ) apenas parte da área operacional (produção, atendimento, prestação de serviços);

( ) nenhuma área da empresa.

Q3. Em sua opinião, qual a probabilidade de que, nos próximos 50 anos, as novas tecnologias (robôs, computadores, inteligência artificial etc.) podem vir a fazer muito do trabalho que hoje são feitos por seres humanos?

( ) Tenho certeza de que isso irá acontecer;

( ) Acredito que provavelmente isso irá acontecer;

( ) Acredito que provavelmente isso NÃO irá acontecer;

( ) Tenho certeza de que isso NÃo irá acontecer;

( ) Não sei, ou não quero responder.

Q4-6. Se as novas tecnologias (robôs, computadores, inteligência artificial etc.) fossem capazes de fazer grande parte do trabalho que atualmente é feito por humanos, você acha que:

* haveria novos empregos e melhor remuneração?

* as pessoas comuns teriam dificuldade em conseguir emprego?

* a economia seria muito mais eficiente?

( ) Sim, provavelmente;

( ) Não, não é provável;

( ) Não sei, ou não quero responder. 
Q7. Em sua opinião, qual a probabilidade da profissão que você exerce hoje ou daquela que você irá exercer no futuro, seja totalmente feita por máquinas, robôs ou inteligência artificial?

( ) Tenho certeza de que isso irá ocorrer;

( ) Acredito que a probabilidade seja alta;

( ) Acredito que a probabilidade seja baixa;

( ) Acredito que a probabilidade seja zero.

Q8. Você acredita que está se preparando adequadamente para o mercado de trabalho do futuro?

( ) Totalmente;

( ) Suficientemente;

( ) Razoavelmente;

( ) Pouco;

( ) Nem um pouco.

Q9-12. Qual é a responsabilidade de *indivíduos, *governo, *escolas e *empresas para garantir que o profissional tenha as habilidades e educação necessárias para ser bem-sucedido no futuro?

( ) Muita responsabilidade;

( ) Alguma responsabilidade;

( ) Pouca responsabilidade;

( ) Nenhuma responsabilidade;

( ) Não sei, ou não quero responder.

Recebido em 4 de junho de 2021. Revisado em 14 de setembro de 2021. Aprovado em 27 de setembro de 2021. 